\title{
Comparative Assessment of the Effect of Diminazene Aceturate and Imidocarb Dipropionate on Haematology and Serum Biochemical Parameters of Apparently Healthy Nigerian Dogs
}

\author{
J.O. Olukunle", C.T. Oyedoyin ${ }^{*}$, E.B. Jacobs ${ }^{* *}$, E.O. Adeleye ${ }^{*}$, T.O. Omobowale ${ }^{* * * *}$ \\ and R.O.A. Arowolo* \\ *Department of Veterinary Physiology and Pharmacology, College of Veterinary \\ Medicine, University of Agriculture, Abeokuta, Nigeria. ${ }^{* *}$ Department of Veterinary \\ Medicine and Surgery, College of Veterinary Medicine, University of Agriculture, \\ Abeokuta, Nigeria. ${ }^{* * *}$ Department of Veterinary Medicine, Faculty of Veterinary \\ Medicine, University of Ibadan, Ibadan, Nigeria
}

\begin{abstract}
D IMINAZENE aceturate (DIAC) and Imidocarb diproprionate (IMD) are drugs of choice in the management of some heamoprotozoan diseases. In this study we evaluated the comparative effects of the two drugs on the haematology and serum biochemical parameters of Nigerian local dogs. Fifteen (15) apparently healthy Nigerian dogs were used in this study. Dogs were randomly divided into three equal groups. Group A received no treatment and served as control. Groups B received intramuscular injection $3.5 \mathrm{mg} / \mathrm{kg}$ DIAC and group $\mathrm{C}$ received $5.5 \mathrm{mg} / \mathrm{kg}$ of IMD via intramuscular injection. Blood samples were collected 24 hours after the administration of the drugs. through the cephalic vein from each dog for haematology and serum analysis. Packed cell volume (PCV), white blood cell (WBC), neutrophil, lymphocytes were counted. Serum aspartate aminotransferase (AST), alanine amino transferase (ALT), calcium, and chloride were measured. The overall results revealed that neither DIAC nor IMD treated groups caused any significant deviations from the untreated controls in all the above parameters assayed. In conclusion, both drugs are safe to use for treating heamoprotozoan diseases in the same dosage.
\end{abstract}

Keywords: Diminazene aceturate, Imidocarb diproprionate, Blood protozoa, Dogs, Biochemical changes, C.B1. picture.

\section{Introduction}

Diminazene aceturate (DIAC, $\mathrm{C}_{14} \mathrm{H}_{15} \mathrm{~N}_{7}$ ) is a drug which has been used for well over 60 years for the treatment of trypanosomiasis [1]. Chemically, the drug is an aromatic diamidine possessing two amidinophenyl moeities linked by a triazene bridge [2]. The main aim of the synthesis of this compound was to produce a chemical that would be used in combating diseases caused by blood parasite infections such as Trypanosoma sp and Babesia sp [3]. DIAC has been utilized in as the main trypanocidal and babesicidal drug in different regions of the world because of its excellent therapeutic index $[4,5,6,7]$. Even though DIAC has been widely studied over the last 60 years, there have been extensive studies in recent times on it owing to its therapeutic potentials and pleiotropic effects $[3,8]$. Apart from its widely acknowledged antiprotozoal activities, some recent studies have demonstrated its cardioprotective effects. DIAC has been reported to be an activator of Angiotensin Converting Enzyme 2 (ACE-2), a peptide which has beneficial effects on the cardiovascular system $[9,10]$, and stimulate the protective activities of the Renin-Angiotensin System, leading to the cleavage of Angiotensin II (Ang-II) to Ang-(1-7) [11].

Imidocarb dipropionate (IMD) is a drug widely used in Africa for the treatment of babesiosis in cattle and sheep, anaplasmosis in cattle and other tick-borne diseases. Imidocarb has been approved in a number of countries since the early 1970's for the treatment of protozoan diseases [12]. Administration of high IMD doses has been reported to cause severe depression, cyanosis, hepatic necrosis, collapse and death in dogs [13]. It was reported to cause 
tachycardia, diarrhoea and death in dogs used for pharmacokinetic studies [14]. Toxicity symptoms of IMD are related to its cholinesterase inhibitor activity $[14,15]$.

Despite the wide use of these two drugs for the treatment of animal haemoparasite infections and the recorded efficacy, there is a dearth of information on the haematological and serum biochemical changes that may occur following their use in apparently healthy dogs.

This study was undertaken to determine the effects of the administration of DIAC and IMD on some haematological and serum biochemical parameters of apparently healthy Nigerian dogs,

\section{Material and Methods}

\section{Experimental animals}

A total of 15 apparently healthy Nigerian dogs obtained from household units were used in this study. The dogs were acclimated to their new environment for a period of 2 weeks. All dogs were regularly physically examined before experiment to check for external parasites such as ticks and fleas. They were also checked for discharges and mucous membrane examined for abnormalities. They were fed the same diet of home cooked meal, and allowed free access to fresh drinking water ad-libitum. The dogs were equally and randomly divided into 3 groups each containing 5 animals. All experimental protocols carried out on the animals were in accordance with the internationally accepted principles for the experimental animal usage and were approved by Ethics Committee on the Laboratory Animal Use of the College of Veterinary Medicine of University of Agriculture, Abeokuta.

\section{Drug administration and sample collection}

Group A represented the untreated control dogs, while groups B and C dogs were treated intramuscularly with DIAC at the dosage of $3.5 \mathrm{mg} / \mathrm{kg}$ and IMD at the dosage of $5.5 \mathrm{mg} / \mathrm{kg}$, respectively. About 24 hours after the administration of the drugs, $5 \mathrm{mls}$ of blood samples was collected through the cephalic vein from each dog for haematology and serum analysis Haematological parameters (packed cell volume (PCV), white blood cell (WBC), neutrophil, and lymphocytes count) [16], RBC count [17] were determined by the haematocytometry method and the erythrocyte indices were obtained by calculation.
For serum biochemical parameters, aspartate amino transferase (AST) and alanine amino transferase (ALT) [18], blood urea nitrogen (BUN), and creatinine [19]. were done

\section{Statistical analysis}

Data was subjected to statistical analysis using student t-test at a significance level of 5\%. Results were expressed as (mean $\pm \mathrm{SD}$ ). (Simple one way ANOVA)

Please add the reference for the statisticalanalysis

\section{$\underline{\text { Results }}$}

Results of the haematological and serum biochemical parameters measured in this study are presented in Figures 1-11. Diminazene aceturate caused a slight reduction in PCV (37\%), while Imidocarb caused a slight increase $(42 \%)$ in the value of $\mathrm{PCV}$ when compared with the control group (38\%) (Fig. 1).

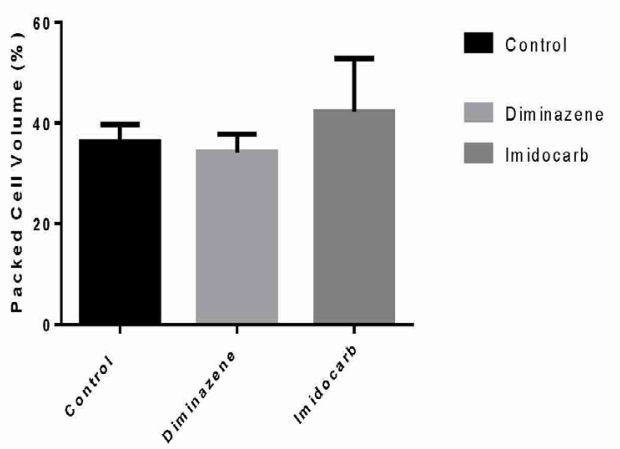

Fig. 1. Mean values of packed cell volume following treatment with DIAC and IMD.

RBC values were slightly reduced in DIAC group $\left(5.4 \times 10^{6} / \mathrm{Ul}\right)$ while it increased slightly in IMD treated group $\left(5.7 \times 10^{6} / \mathrm{Ul}\right)$ when compared with the control group $\left(5.6 \times 10^{6} / \mathrm{Ul}\right)$ (Fig.2). There were no statistically significant change in the values of WBC count, neutrophil count and lymphocyte count of the DIAC and IMD treated groups when compared with the values of animals in the control group (Fig. 3-5). May be this require a long time treatment not only one shot. 


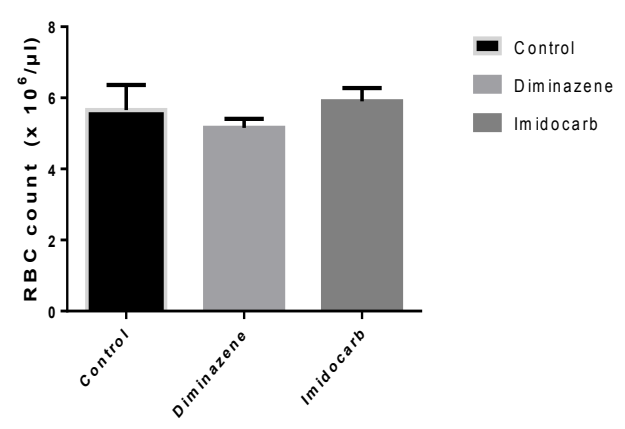

Fig. 2. Mean values of red blood cell counts following treatment with DIAC and IMD

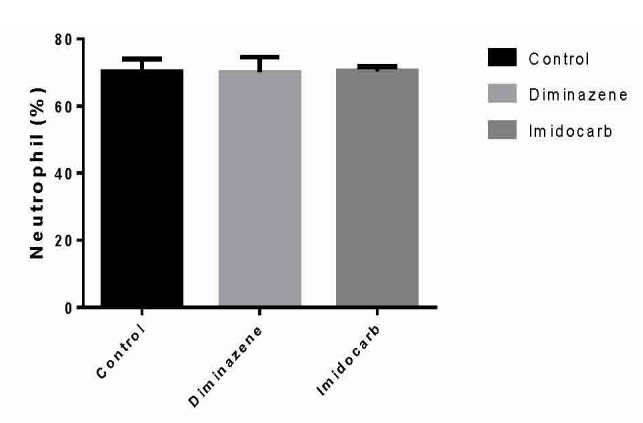

Fig. 4. Mean values of neutrophil count following treatment with DIAC and IMD .

The serum chemistry revealed that DIAC caused slight increase in the values of BUN $(12 \mathrm{mg} / \mathrm{dl})$ and creatinine $(0.7 \mathrm{mg} / \mathrm{dl})$, while IMD administration produced BUN value of $(11.5 \mathrm{mg} / \mathrm{dl})$ and creatinine value of $(0.62 \mathrm{mg} / \mathrm{dl})$ when compared with the values $(11 \mathrm{mg} / \mathrm{dl})$ and $(0.6 \mathrm{mg} / \mathrm{dl})$ respectively in the control animals (Figs 6, 7).

Lliver enzymes like ALT and AST activities were slightly reduced by the effect of DIAC (24U/L) and IMD (25u/l) when compared to the control group (26U/1) (Fig.8,9).

Blood calcium level was assayed to be $5.5 \mathrm{mg} / \mathrm{dl}$ for the DIAC treated group and there

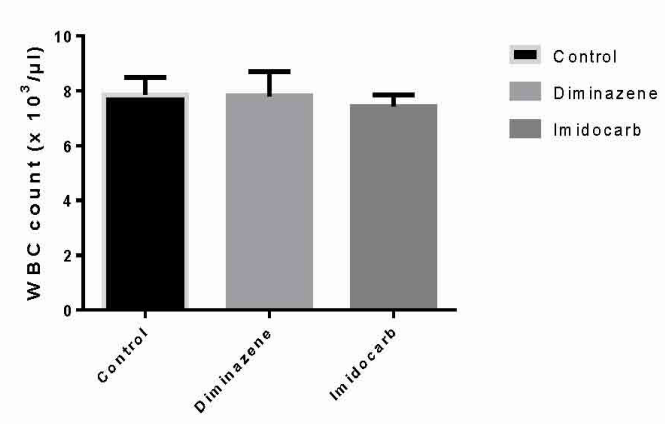

Fig. 3. Mean values of white blood cell counts following treatment with DIAC and IMD.

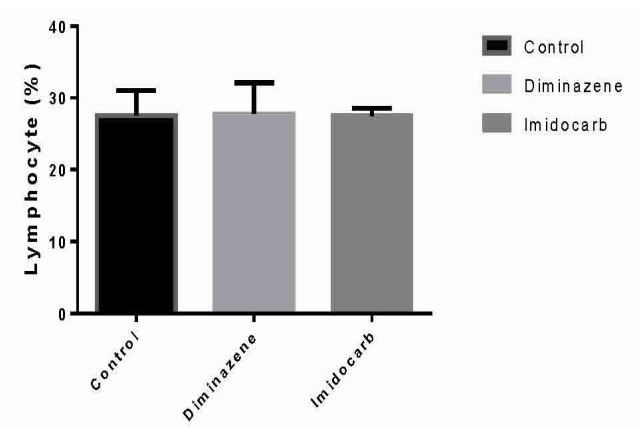

Fig. 5. Mean values of lymphocyte count following treatment with DIAC and IMD .

was slight increase in blood calcium level for the IMD treated group $(6.0 \mathrm{mg} / \mathrm{dl})$ when compared to the control group (5.5.mg/dl) (Fig. 10). The chloride value for DIAC group was slightly reduced $(88 \mathrm{mEq} / \mathrm{L})$, but the chloride value in IMD treated group was equivalent to the values obtained from the animals in the control group (90mEq/L) (Fig.11).

Overall, when compared with the controls, neither DIAC nor IMD treat group caused any significant deviations from the untreated controls. 


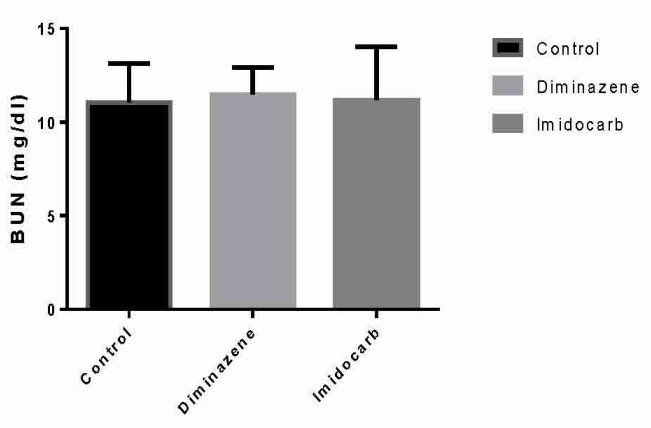

Fig. 6. Mean values of blood urea nitrogen following treatment with DIAC and IMD.

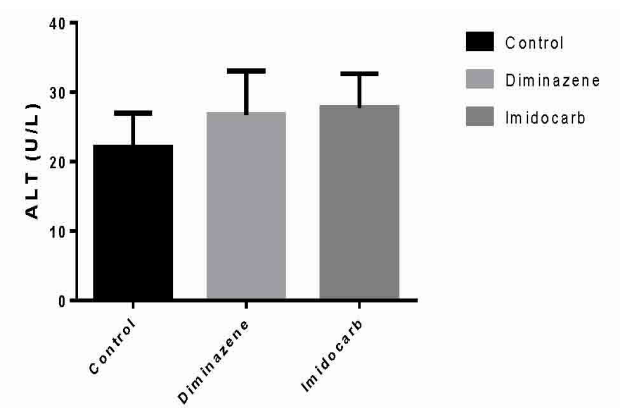

Fig. 8. Mean values of Alanine transaminase activity following treatment with DIAC and IMD.

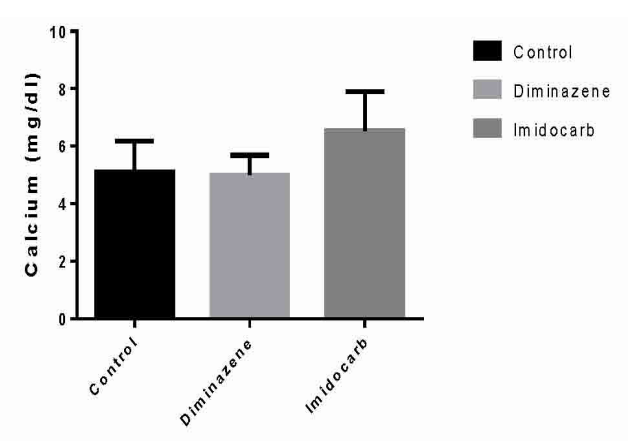

Fig.10. Mean values of calcium concentration following treatment with DIAC and IMD.

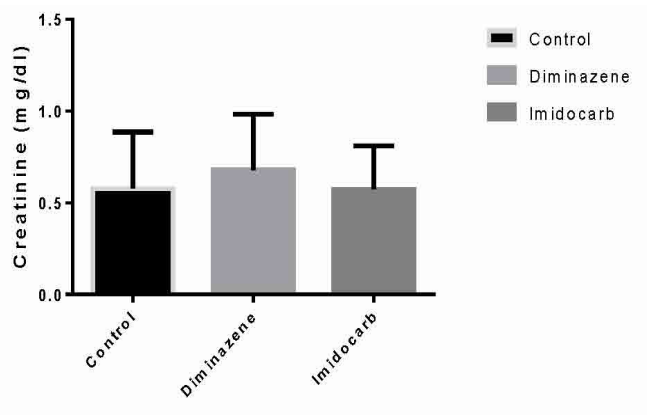

Fig.7. Mean values of creatinine concentration following treatment with DIAC and IMD.

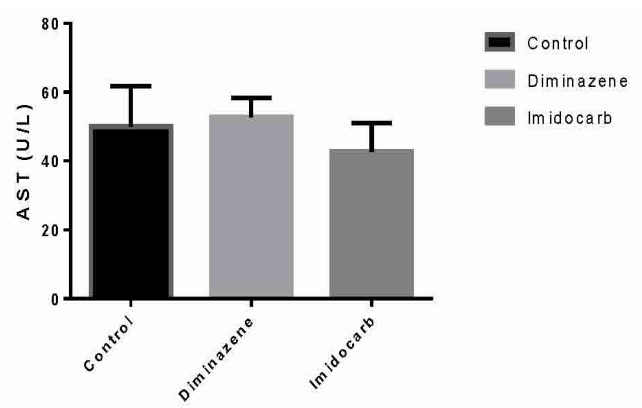

Fig.9. Mean values of Aspartate aminotransferase activity following treatment with DIAC and IMD.

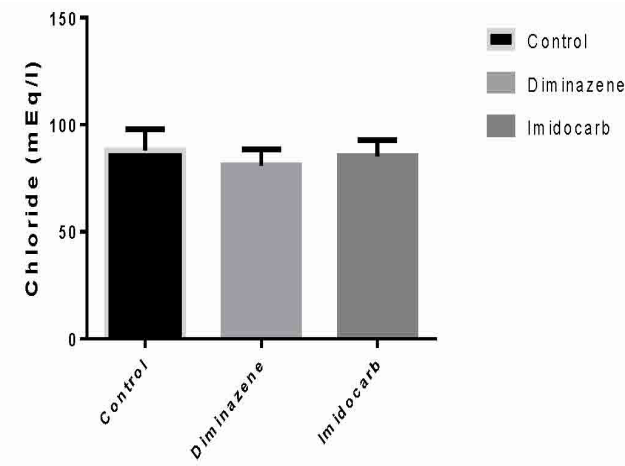

Fig. 11. Mean values of chloride concentration following treatment with DIAC and IMD. 


\section{Discussion}

From our study, the administration of DIAC and IMD did not adversely alter the haematological and serum biochemical profiles of Nigerian local dogs This may refer to the binding of bout $70 \%$ of diminazene to red blood cell as well as purified haemoglobin [20], with the absence of any records on its toxic effect on red blood cell, serum and plasma enzymes. In agreement with our results, diminazene aceturate ameliorated the anaemia caused by Trypanosomal brucei brucei infection in rats[21], has the capacity to improve blood components in Trypanosomes infected rats[22], and caused a generalized increase in WBC of dogs treated with various doses of diminazene aceturate [23].

You can write the authors names only before their reference number

Bashir et al. [24] reported that the administration of Imidocarb caused no significant changes in complete blood count $(\mathrm{CBC})$, bilirubin concentration and (BUN) between pre- and post- treatment periods in dogs. Contrary, a significant decrease in the total erythrocyte count and significant decrease in the haemoglobin concentration was recorded in goats treated with imidocarb [25]. The significant increase in mean platelet volume in dogs suffering from babesiosis and treated with imidocarb [26] is in consonance with the elevation in platelets count of babesia infected dogs and treated with imidocarb [27].

\section{Conclusions}

From our results on the haematology and serum biochemistry assessment of the local breed of dogs treated with DIAC and IMD, this study concludes that the administration of diminazene aceturate and imidocarb dipropioniate caused no significant change to the haematology and serum biochemistry of apparently healthy Nigerian local breeds of dogs and are safe to use.

Acknowledgements:

The author appreciates the efforts of all members who participated in this study.

Funding statements

The authors declare that this work is authors selffunded.

Conflicts of interest:

The authors declare that there are no conflict of interest.

\section{References}

1. Kuriakose, S. and Uzona, J.E. Diminazene aceturate (Berenil), a new use for an old compound. Inter. Immunopharm, 21, 342-345 (2014).

2. Peregrine, A.S. and Mamman, M. Pharmacology of Diminazene: a review. Acta Trop., 54 (3-4), 185-203 (1993).

3. da Silva Oliveira, G.L. and de Freitas, R.M. Diminazene aceturate - an antiparasitic drug of antiquity: advances in pharmacology and therapeutics. Pharmac. Res., 102,138-157 (2015).

4. Atsriku, C., Watson, D.G., Tettey, J.N.A., Grant, M.H., Skellern, G.G. Determination of diminazene aceturate in pharmaceutical formulations by HPLC and identification of related substances by LC/MS. J. Pharmaceu. and Biomed. Anal., 30,979-986 (2002).

5. Delespaux, V. and Koning, H.P. Drugs and drug resistance in African trypanosomosis. Drug Resist. Updates, 10, 30-50 (2007).

6. Yabsley, M. J. and Shock, B. C. Natural history of zoonotic Babesia: role of wildlife reservoirs. Inter J. Parasitol. Par. Wildl. 2, 18-31 (2013).

7. Guswanto, A., Sivakumar, T., Rizk, M.A., Elsayed, S.A.E., Youssef, M.A., ElSaid, E.E.S., Yokoyama, N. and Igarashi, I. Evaluation of a fluorescence-based method for antibabesial drug screening. Antimicrob Agents Chemo,, 58,47134717 (2014).

8. Baldissera, M.D., Gonçalves, R.A., Sagrillo, M.R., Grando, T.H., Ritter, C.S., Grotto, F.S., Brum GF, da Luz SC, Silveira, S.O., Fausto, V.P., Boligon, A. A., Vaucher, R. A., Stefani, L. M., da Silva, A.S., Souza, C.F. and Monteiro, S.G. Effects of treatment with the anti-parasitic drug Diminazene aceturate on antioxidant enzymes in rat liver and kidney. Naunyn-Schmiedeberg's Archives of Pharmacology, 389, 429-438 (2016).

9. Donoghue, M., Hsieh, F, Baronas, E., Godbout, K., Gosselin, M. and Stagliano, N. A novel angiotensin - converting enzyme-related carboxypeptidase (ACE2) converts angiotensin I to angiotensin 1-9. Circul, Res., 87, E1-E9 (2000).

Egypt. J. Vet. Sci. Vol. 49, No.2 (2018) 
10. Tipnis, S.R., Hooper, N.M., Hyde, R.., Karran, E. Christie, G. and Turner, A.J. A human homolog of angiotensin-converting enzyme.Cloning and functional expression as a captopril-insensitive carboxypeptidase. J. Biol. Chem., 275, 3323833243 (2000).

11. Kulemina, L.V. and Ostrov, D.A. Prediction of off-target effects on angiotensin converting enzyme 2, J. Biomol. Scre., 16, 878-885 (2011).

12. Atif, F.A., Khan, M.S., Khan, M.A., Ashraf, M. and Avais, M. Chemotherapeutic efficacy of oxytetracycline, enrofloxacin and Imidocarb for the elimination of persistent Anaplasma marginale infection in naturally infected Sahiwal cattle. Pakistan J. Zool., 44 (2), 449-456 (2012).

13. Kock, N. and Kelly, P. Massive hepatic necrosis associated with accidental imidocarb dipropionate toxicosis in a dog. J. Compar. Pathol., 104, 113116 (1991)

14. Abdullah, A.S., Sheikh-Omar, A.R., Baggot, J.D. and Zamri, M. Adverse effects of imidocarb dipropionate (Imizol) in a dog. Vet. Res. Com., 8(1), 555-559 (1984).

15. Vial, H.J. and Gorenflot, A. Chemotherapy against babesiosis. Veterinary Parasitology, 138, 147-160 (2006).

16. Schalm, O.W., Jain, N.C. and Caroll, E.J. Veterinary Haematology, $3^{\text {rd }}$ ed., Lea and Fabiger, Philadelphia. pp. 144 -167 (1975).

17. Jain, N.C. Schalm's Veterinary Haematology, $4^{\text {th }}$ ed., Lea and Fabiger, Philadelphia, pp. 564-575. (1986).

18. Sigma Diagnostics Quantitative Colorimetric Determination in Serum, Plasma or Cerebrospinal Fluid (Procedure No. 505) (1985).
19. Varley, H., Gewenlock, A.H and Bell, M. Practical Clinical Biochemistry, vol.1, $5^{\text {th }}$ ed., CBS publisher and distributors., Delhi, 741-742. (1991)

20. Alvi, N. K, Haqqi T. M. and Hadi, S. M. Irreversible binding of Berenil, a trypanocidal drug to blood proteins. Indian J. Exper. Biol., 23, 172-173 (1985).

21. Kobo, P.I., Ayo, J.O., Tagang, A., Zezi A.U. and Maikai, V.A. Haematological Changes in Trypanosoma Brucei Brucei Infected Wistar Rats Treated with a Flavonoid Mixture and or Diminazene Aceturate. Biol. Med., 6, 213. (2013). doi:10.4172/0974-8369.1000213

22. Sulaiman, F.A. and Adeyemi, O.S. Changes in haematological indices and protein concentration in $\mathrm{T}$. brucei infected rats treated with homidium chloride and diminazene aceturate. Excli. J., 9, 3945 (2010).

23. Othman, T. The toxic effects of multiple doses of Diminazene aceturate on the haematological values of rats. Nigerian J. Ani. Prod., 21, 146-148 (1994).

24. Bashir, T., Rabbani, I., Khan, M.A., Zaman, M.Q., Yousaf, M.S., Khan, M.I. and Sharif F. Effect of Anti-Piroplasm Drug on Various Physiological Indices in Healthy Mongrel Dogs. J. Vet. and Ani. Sci., 4 (1), 5-10 (2014).

25. Singh, T., Varshneya, C., Bahga, H. S. and Sharma, L.D. Adverse effects of imidocarb dipropionate administration in goats. Acta Veterinaria (Beograd), 40 (2-3), 119-127 (1990).

26. Zvorc, Z., Rajaf, R.B., Kules, J. and Mrljak, V. Erythrocyte and platelet indices in babesiosis of dogs. Veterinarski Archiv, 80 (2), 259-267 (2010).

27. Arthis, A. and Tresamol, P.V. Molecular identification of Babesia Canis Vogelis and its therapeutic management with imidocarb. Inter. $J$. Agric. Sci. \& Vet. Med., 5 (1), 87-90 (2017).

(Received 23/01/2018; accepted 08/07/2018) 


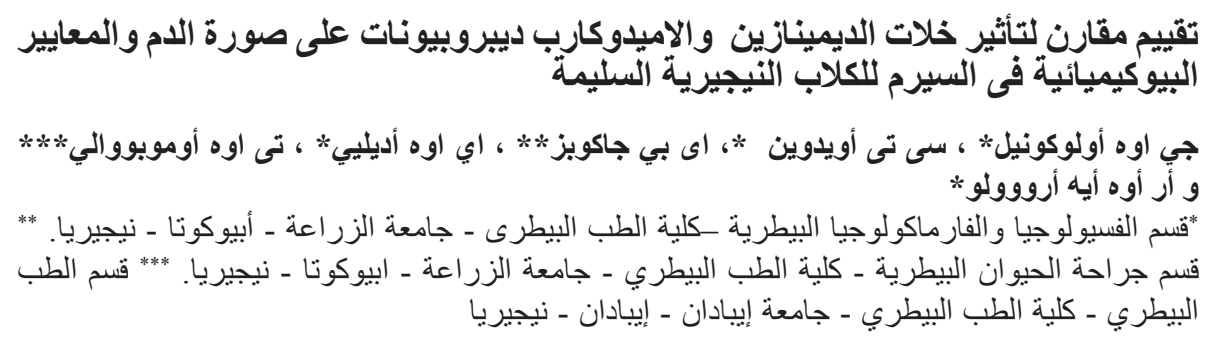

خلات الديمانزين و الاميدوكارب هي أدوية مفضلة في علاج بعض أمر اض البروتوزوا فى الدم ـ في هذه الدراسة

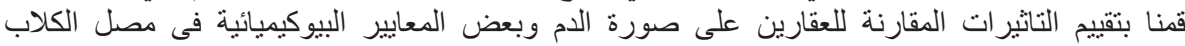

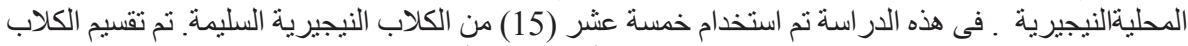

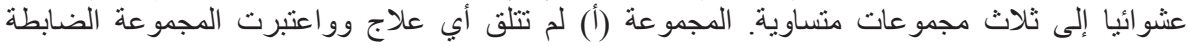

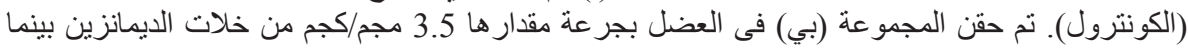

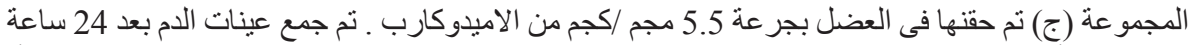

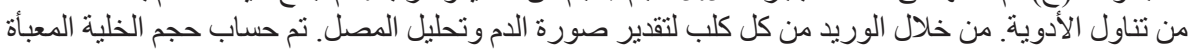
(PCV) aminotransferase

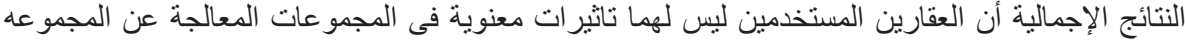

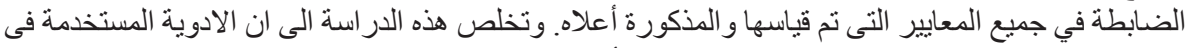

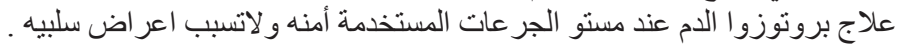
الكلمات الداله: بروتوزوا الدم ، العقاقير ، الكلاب ، صورة الدم ، البيوكيميائية ، الاميدازول. 